\title{
Effects of different chemical additives on biodiesel fuel properties and engine performance. A comparison review
}

\author{
Obed Majeed Ali ${ }^{1, a}$, Rizalman Mamat ${ }^{1}$, Nik R. Abdullah² ${ }^{2}$ Abdul Adam Abdullah ${ }^{1}$, Fitri Khoerunnisa ${ }^{3}$, and Ratnaningsih \\ Eko Sardjono ${ }^{3}$ \\ ${ }^{1}$ Faculty of Mechanical Engineering, Universiti Malaysia Pahang, 26600, Pekan, Pahang, Malaysia \\ ${ }^{2}$ Faculty of Mechanical Engineering, Universiti Teknologi MARA (UiTM) 40450 Shah Alam, Selangor, Malaysia \\ ${ }^{3}$ Department of Chemistry, Indonesia University of Education, Bandung 40154, Indonesia
}

\begin{abstract}
Biodiesel fuel can be used as an alternative to mineral diesel, its blend up to $20 \%$ used as a commercial fuel for the existing diesel engine in many countries. However, at high blending ratio, the fuel properties are worsening. The feasibility of pure biodiesel and blended fuel at high blending ratio using different chemical additives has been reviewed in this study. The results obtained by different researchers were analysed to evaluate the fuel properties trend and engine performance and emissions with different chemical additives. It found that, variety of chemical additives can be utilised with biodiesel fuel to improve the fuel properties. Furthermore, the chemical additives usage in biodiesel is inseparable both for improving the cold flow properties and for better engine performance and emission control. Therefore, research is needed to develop biodiesel specific additives that can be adopted to improve the fuel properties and achieve best engine performance at lower exhaust emission effects.
\end{abstract}

\section{Introduction}

Fossil fuel contributes to the prosperity of the worldwide economy since it is widely used due to high combustion efficiency, reliability, adaptability and costeffectiveness. However, the reserves of petroleum-based fuels are limited and on the verge of reaching their maximum production. Although the majority of the renewable energy technologies are more eco-friendly than conventional energy, the use of these technologies is still limited primarily to stationary operations, mainly due to technological limitations and poor economics [1]. The current alternative to diesel fuel can be biodiesel. It can offer many benefits, including the reduction of greenhouse gas emissions, regional development and social structure, especially to developing countries [2,3].

Biodiesel is a renewable and environmental friendly alternative diesel fuel for diesel engine [4,5]. It is an oxygenated fuel which contains $10-15 \%$ oxygen by weight $[6,7]$, and is a sulphur-free fuel. These facts lead biodiesel to complete combustion and less exhaust emissions than diesel fuel. Biodiesel has a higher viscosity, density, pour point, flash point and cetane number than diesel fuel. On the other hand, the energy content or the net calorific value of biodiesel is about $12 \%$ less than that of diesel fuel on a mass basis, causing lower engine speed and power [8-11]. The use of biodiesel instead of the conventional diesel fuel significantly reduces exhaust emissions such as carbon dioxide $\left(\mathrm{CO}_{2}\right)$, [12,13] particulate matter (PM), carbon

\footnotetext{
${ }^{\mathrm{a}}$ Corresponding author: obedmajeed@gmail.com
}

monoxide $(\mathrm{CO})$, sulphur oxides $\left(\mathrm{SO}_{\mathrm{X}}\right)$, and unburned hydrocarbons (HC) $[14,15]$. On the other hand, biodiesel has a higher nitrogen oxide $\left(\mathrm{NO}_{\mathrm{X}}\right)$ emissions than diesel fuel $[16,17]$. The main disadvantages of biodiesel are injector coking, engine compatibility, and high price [18]. The effects of oxidative degradation caused by contact with ambient air (auto oxidation) during long-term storage present a legitimate concern in terms of maintaining the quality of biodiesel fuel.

A key property of biodiesel currently limiting its application to blends of $20 \%$ or less is its relatively poor low-temperature properties [19,20]. Petroleum diesel fuels are plagued by the growth and agglomeration of paraffin wax crystals when ambient temperatures fall below the fuel's cloud point. These solid crystals may cause start up problems such as filter clogging when ambient temperatures drop to around -10 to $-15{ }^{\circ} \mathrm{C}$ [21]. While the cloud point of petroleum diesel is reported as $16{ }^{\circ} \mathrm{C}$, biodiesel typically has a cloud point of around 0 ${ }^{\circ} \mathrm{C}$, thereby limiting its use to ambient temperatures above freezing $[22,23]$.

Published research has shown that the physical properties of biodiesel can be improved by the use of different additives, so that it can solve the problems associated with cold flow properties of biodiesel for their large scale usage in diesel engines. A number of additives have been tried by different researchers for improving the performance and also reducing emissions from diesel engines. The objective of this study to developed data base for the used chemical additives with biodiesel under 
certain categories and discuss their suitability for each type of biodiesel according to their properties.

\section{Chemical additives}

Several approaches have been proposed to improve the low temperature properties of biodiesel, including: blending with petroleum diesel; the use of additives; and the chemical or physical modification of either the oil feedstock or the biodiesel product [24]. Blending with petroleum diesel is only effective at low biodiesel proportions (up to $30 \%$ by vol.) with cloud points to around $-10{ }^{\circ} \mathrm{C}[23]$. Clearly, blends with petroleum diesel do not change the chemical nature and therefore the properties of biodiesel will not facilitate their use at higher concentrations. Since the aim must be to maximize biodiesel utilization, petroleum blends with biodiesel will not be discussed further in this review. The use of additives can be further classified into traditional petroleum diesel additives and emerging new technologies developed specifically for biodiesel. Several authors have published different works to improve the low-temperature properties of biodiesel by the usage of different additives for their convenient handling and usage at different climatic conditions. Traditional petroleum diesel additives can be described as either pour point (PP) depressants or wax crystalline modifiers. Pour point depressants were developed to improve the pump ability of crude oil and do not affect nucleation habit. Instead, these additives inhibit crystalline growth thereby eliminating agglomeration. They are typically composed of low molecular weight copolymers similar in structure to aliphatic alkane molecules, the most widely applied group being copolymers of ethylene vinyl ester. Wax crystalline modifiers, as the name suggests, are copolymers that disrupt part of the crystallization process to produce a larger number of smaller, more compact wax crystals [25].

\subsection{Effect of chemical additives on fuel properties}

Natural and synthetic antioxidant are often added to protect oil and fats by minimizing or retarding oxidation $[26,27]$. Several studies have been conducted on both types of additives to improve cold flow properties for blends and pure biodiesel. For example, the pour point of neat soybean methyl ester was lowered by as much as 6 ${ }^{\circ} \mathrm{C}$. Similar improvements in cold filter plugging point (CFPP) were achieved but no discernible improvement in $\mathrm{CP}$ was reported, as may have been expected when taking into account their mode of action. As previously stated, a potential mechanism for reducing the $\mathrm{CP}$ of biodiesel is the use of bulky moieties that disrupt the orderly stacking of ester molecules during crystal nucleation. Details of experimental results were reported [28] to improve the low-temperature performance of palm oil products, with emphasis on non-food uses, and to find some additives (synthesized or commercially available) suitable to reduce the pour point and cloud point values of palm oil products. The samples studied in this research include palm olein (PO), super olein (SO), palm oil methyl esters (POME), palm kernel oil methyl esters (PKOME), a blend of POME and $\mathrm{PO}$ at a 2:1 ratio (POMEPO), a blend of POME and SO at a 2:1 ratio (POMESO), a blend of $\mathrm{PKOME}$ and $\mathrm{PO}$ at a 2:1 ratio (PKOMEPO) and a blend of PKOME and SO at a 2:1 ratio (PKOMESO). Among the additives studied in this research were Tween-80, dihydroxy fatty acid (DHFA), acrylated polyester prepolymer, palm-based polyol (PP), a blend of DHFA and $\mathrm{PP}$ at a 1:1 ratio (DHFAPP), an additive synthesized using DHFA and ethyl hexanol (DHFAEH), and castor oil ricinoleate. All the additives used showed satisfactory results, with more significant reductions of pour point and cloud point values observed for POME, PKOME, POMEPO, POMESO and PKOMESO samples. The biggest reduction of the pours point value in this research was about $7.5{ }^{\circ} \mathrm{C}$ (by the addition of $1.0 \%$ DHFA to POMEPO), while the biggest reduction of the cloud point value was about $10.5{ }^{\circ} \mathrm{C}$ (by the addition of $1.0 \%$ DHFA $+1.0 \%$ PP to POME). The significant reductions in pour point and cloud point values of POME, PKOME, POMEPO, POMESO and PKOMESO by the additives used indicate that the additives might be able to improve the low-temperature properties of palm oil products, for instance biodiesel. They speculated that the effectiveness in particular of the polyhydroxy compounds was due to the interaction between the hydroxy groups of the additives and the samples. Unfortunately, a large increase in the viscosity of the blends was reported. An addition of $1.0 \%$ PP to palm oil methyl ester increased its viscosity from $29.5 \mathrm{cP}$ to $42.2 \mathrm{cP}$. Some effort has also been made to utilize the major by-product of biodiesel manufacture, glycerol, by reacting it with isobutylene to produce butyl ethers of glycerol [29]. A CP of $-5{ }^{\circ} \mathrm{C}$ for $12 \%$ butyl ether and methyl ester was claimed. Further improvement in the low temperature properties of the palm biodiesel diesel blend at $3{ }^{\circ} \mathrm{C}$ was achieved by adding $1 \%$ of a palm based additive [30].

\subsection{Effect chemical additives on oxidation stability}

Oxidative stability of biodiesel was improved by adding natural and synthetic antioxidants at the varying concentrations between 250 and 1000 ppm [31-33]. The various natural and synthetic antioxidants $[\alpha$-tocopherol $(\alpha-\mathrm{T})$, butylated hydroxyanisole (BHA), butyl-4methylphenol (BHT), tert-butylhydroquinone (TBHQ), 2, 5-di-tert-butyl-hydroquinone (DTBHQ), ionol BF200 (IB), propylgallate (PG), and pyrogallol (PY)] improve the oxidative stability of soybean oil (SBO), cottonseed oil (CSO), poultry fat (PF), and yellow grease (YG) based biodiesel. The results indicated that different types of biodiesel had different natural levels of oxidative stability, indicating that natural antioxidants play a significant role in determining oxidative stability. Moreover, PG, PY, TBHQ, BHA, BHT, DTBHQ, and IB could enhance the oxidative stability for these different types of biodiesel. They also identified that antioxidant activity increased with increasing concentration. The induction period of SBO-, CSO-, YG-, and distilled SBO- 
based biodiesel could be improved significantly with PY, PG and TBHQ, while PY, BHA, and BHT showed the best results for PF-based biodiesel. They concluded that the effect of each antioxidant on biodiesel differs depending on different feedstock. Further they identified that the effect of antioxidants on B20 and B100 was similar; suggesting that improving the oxidative stability of biodiesel can effectively increase that of biodiesel blends. The oxidative stability of untreated SBO-based biodiesel decreased with the increasing indoor and outdoor storage time, while the induction period values with adding TBHQ to SBO-based biodiesel remained constant for up to 9 months. Although $\alpha$-tocopherol showed very good compatibility in blends, it was significantly less effective than the synthetic antioxidants screened in this work. The cetane improvers DTBP and EHN are effective in reducing NOx by $4 \%$ in B20 blends. DTBP is also effective in NOx reduction for B100 fuels but not in proportion to the NOx reduction observed for B20 blends. They observed that cetane improvers act largely to lower the NOx produced during the burning of the petroleum diesel fuel. The antioxidant TBHQ significantly reduced $\mathrm{NOx}$ but also caused a small increase in particulate matter.

The effect of antioxidants addition on pollutant emissions from the combustion of palm oil methyl ester blends with No. 2 diesel was investigated in a nonpressurised, water-cooled combustion chamber [34]. Antioxidant additives butylated hydroxyanisole (BHA), butylated hydroxytoluene (BHT) and tert-butyl hydroquinone (TBHQ) were individually dissolved at varying concentrations in B10 and B20 fuel blends for testing. Both BHA and TBHQ were effective in lowering the nitric oxide (NO) emission produced, where their concentrations in the fuel blends were shown to scale proportionately to NO levels in the flue gas. However, the addition of BHT to both fuel blends, increased the generation of NO during combustion. BHA was found to decrease the carbon monoxide ( $\mathrm{CO}$ ) levels when added to B10 and B20, while both BHT and TBHQ were observed to raise $\mathrm{CO}$ formation at all test points. With the proper selection of additives type and quantity for application to specific biodiesel blends, this simple measure has been shown to be an effective pollutant control strategy which is more economical than other existing technologies. The addition of the synthetic antioxidant tertbutylhydroquinone [35] at the concentration of 300 $\mathrm{mg} / \mathrm{kg}$ with cottonseed biodiesel was sufficient to obtain acceptable oxidation stability values ( $>6$ hours). Thermogravimetric analysis was also performed and similar profiles were verified for both ethylic and methylic biodiesels. Therefore, this work demonstrates the feasibility of using the ethanolic route to produce cottonseed oil biodiesel.

Other research [36] studied experimentally and compared the effect of antioxidant additives on $\mathrm{NO}_{\mathrm{X}}$ emissions in a jatropha methyl ester fuelled direct injection diesel engine. The antioxidant additives Lascorbic acid, $\alpha$-tocopherol acetate, butylated hydroxytoluene, p-phenylenediamine and ethylenediamine were tested on computerized Kirloskarmake 4 stroke water cooled single cylinder diesel engine of $4.4 \mathrm{~kW}$ rated power. Their results showed that antioxidants considered in their study are effective in controlling the $\mathrm{NO}_{\mathrm{x}}$ emissions of biodiesel fueled diesel engines. A $0.025 \%$ concentration of $\mathrm{p}$-phenylenediamine additive was optimal as $\mathrm{NO}_{\mathrm{x}}$ levels were substantially reduced in the whole load range in comparison with neat biodiesel. However, hydrocarbon and CO emissions were found to have increased by the addition of antioxidants.

The influence of Oxidative stability of palm biodiesel by adding natural and synthetic antioxidants additive were investigated experimentally $[37,38]$. The experimental study conducted on the crude and distilled methyl esters of palm oil and found that crude palm oil has better oxidative stability. They attributed this to the presence of vitamin E (about $600 \mathrm{ppm}$ ), a natural antioxidant in the crude palm oil methyl esters. Natural and synthetic antioxidants were used in this study to investigate the effect on the oxidative stability of distilled palm oil methyl esters. It was found that both types of antioxidant showed beneficial effects in inhibiting the oxidation of distilled palm oil methyl esters. They found that the synthetic antioxidants were found to be more effective than the natural antioxidants as lower dosage (17 times less) was needed to achieve the minimum rancimat induction period of 6 hours as required to meet the European standard for biodiesel (EN 14214).

\subsection{Effect chemical additives on engine performance and emissions}

Many studies investigate the eliminate of biodiesel NOx effect by evaluation of formulation strategies $[39,40]$. This was accomplished by spiking a conventional soy-derived biodiesel fuel with methyl oleate or with cetane improver. The conventional B20 blend produced a NOx increase of $3.5 \%$ relative to petroleum diesel, depending on injection timing. However, when they used a B20 blend where the biodiesel portion contained $76 \%$ methyl oleate, the biodiesel NOx effect was eliminated and a NOx neutral blend was produced. Increasing the methyl oleate portion of the biodiesel to $76 \%$ also had the effect of increasing the cetane number from 48.2 for conventional B20 to 50.4 , but this effect is small compared to the increase to 53.5 achieved by adding 1000ppm of 2-ethylhexyl nitrate (EHN) to B20. They identified that for the particular engine tested, $\mathrm{NO}_{\mathrm{X}}$ emissions were found to be insensitive to ignition delay, maximum cylinder temperature, and maximum rate of heat release. The dominant effect on $\mathrm{NO}_{\mathrm{X}}$ emissions was the timing of the combustion process, initiated by the start of injection, and propagated through the timing of maximum heat release rate and maximum temperature.

Higher brake power produced over the entire engine speed range obtained [41,42] with 1\% 4-nonyl phenoxy acetic acid (NPAA) additive in comparison to blended palm biodiesel B20 and B0 (diesel). The maximum brake power obtained at $2500 \mathrm{RPM}$ is $12.28 \mathrm{~kW}$ from $\mathrm{B} 20$ blended with $1 \%$ additive followed by a $11.93 \mathrm{~kW}(\mathrm{~B} 0)$ and $11.8 \mathrm{~kW}$ (B20). The result implied that the biodiesel with some additives $(\mathrm{B} 20+1 \%)$ shows the best engine 
performance and reduce the exhaust emission including $\mathrm{NO}_{\mathrm{X}}$. They contributed to the increase of fuel conversion efficiency by improving fuel ignition and combustion quality due to the effect of fuel additive in B20 blend.

Other experimental studies [43-45] were carried out to evaluate the effect of Triacetin $(\mathrm{T})$ as an additive with biodiesel on direct injection diesel engine performance and combustion characteristics. By adding triacetin $\left[\mathrm{C}_{9} \mathrm{H}_{14} \mathrm{O}_{6}\right]$ additive to biodiesel, the results showed that the engine knocking problem can be alleviated to some extent and the tail pipe emissions are reduced. A comparative study was conducted using Petro-diesel, biodiesel and additive blends of biodiesel on the engine. Coconut oil methyl ester (COME) was used with an additive at various percentages by volume for all load ranges of the engine viz. at no load, 25,50 and $75 \%$ of full load and at full load. Their results showed that performance is compared with neat diesel in respect of engine efficiency and exhaust emissions. Among the all blend fuels tried, $10 \%$ Triacetin combination with biodiesel shows encouraging results.

Ethanol is a low cost oxygenate with high oxygen content (approximately 35\%) that has been used in biodiesel-ethanol blends [46]. It was reported [47] that the ethanol-diesel-biodiesel fuel blends are stable well below sub-zero temperature and have equal or superior fuel properties to regular diesel fuel ethanol and methanol, as well as products derived from these alcohols, such as ethers, are under consideration or in use as alternative fuels or as an additive biodiesel fuel. Methanol offers very low particulate emissions but the problems are their toxicity, low energy density, low cetane number, high aldehyde emissions, and harmful influence on materials used in engine production. Ethanol seems to be the best candidate as a sole fuel as a component of either gasoline or diesel oil [48]. Until recently ethanol was recognized only as a component of gasoline and not as a component of diesel oils. The properties of ethanol enable applying it also as a component of diesel oil. The potential of oxygenates as a means of achieving zero net $\mathrm{CO}_{2}$ renewable fuel, has resulted in considerable interest in the production and application of ethanol. In many countries such as the United States of America, Canada, Australia, Brazil, South Africa, Denmark, Sweden and others ethanol programs are realized. The research on ethanol programs is directed to identify factors that could influence engine performance and exhaust emissions. An understanding of these factors is necessary for the interpretation of the test results. Methanol can be produced from coal or petrol based fuels with low cost production, but it has very limited solubility in the diesel fuel. On the other hand, ethanol is a biomass based renewable fuel, which can be produced from vegetable materials, such as corn, sugar cane, sugar beets, sorghum, barley and cassava, and it has higher miscibility with diesel fuel [49].

Improvement of the low-temperature operability, kinematic viscosity, and acid value of poultry fat methyl esters were investigated [50] with the addition of ethanol, isopropanol, and butanol. The blends of ethanol in poultry fat methyl esters afforded the least viscous mixtures, whereas isopropanol and butanol blends were progressively more viscous, but still within specifications contained in ASTM D6751 and EN 14214. However, this study identified blends of alcohols in poultry fat methyl esters resulted in failure of the flash point specifications found in ASTM D6751 and EN 14214. Flash points of butanol blends were superior to those of isopropanol and ethanol blends, with the 5 vol\% butanol blend exhibiting a flash point $\left(57^{\circ} \mathrm{C}\right)$ superior to that of No. 2 diesels fuel $\left(52{ }^{\circ} \mathrm{C}\right)$. The most interesting observation is that blends of alcohols in poultry fat methyl esters resulted in an improvement in acid value with increasing content of alcohol. An increase in moisture content of biodiesel was observed with increasing alcohol content, with the effect being more pronounced in ethanol blends versus isopropanol and butanol blends. There wasn't any phase separation of alcohol-methyl esters samples observed in this study at below the ambient temperatures.

The influence of ethanol and kerosene on Mahua methyl ester (Mahua biodiesel) were studied experimentally [51] towards the objectives of identifying the pumping and injecting of these biodiesel in CI engines under cold climates. Effect of ethanol and kerosene on the cold flow behaviour of this biodiesel was studied. A considerable reduction in pour point has been noticed by using these cold flow improvers. Four concentrations of ethanol and kerosene blends, i.e. 5\%, $10 \%, 15 \%$ and $20 \%$, were tested with Mahua biodiesel for cold flow studies. The reduction in cloud point of MME was from $18{ }^{\circ} \mathrm{C}$, to $8{ }^{\circ} \mathrm{C}$, when blended with $20 \%$ of ethanol and up to $5{ }^{\circ} \mathrm{C}$, when blended with $20 \%$ of kerosene. Similarly the reduction in pour point was from $7{ }^{\circ} \mathrm{C}$, to $-4{ }^{\circ} \mathrm{C}$, when blended with $20 \%$ ethanol and up to $-8{ }^{\circ} \mathrm{C}$, when blended with $20 \%$ kerosene. MME with $10 \%$ ethanol and $10 \%$ diesel reduces the pour point from 18 ${ }^{\circ} \mathrm{C}$, up to $-5{ }^{\circ} \mathrm{C}$. The researchers concluded that ethanol and kerosene improve the cold flow properties MME when blended up to $20 \%$. However, higher blends with ethanol are discouraged as it may reduce the overall calorific value. Also ethanol has very low value of cetane number. The results obtained by them showed that dieselethanol blended MME had similar performance at part load and superior performance at full load to that of the diesel. They obtained an average CO\% reduction in $20 \%$ ethanol blended biodiesel over diesel was as high as 50\%, reduction $\mathrm{HC}$ emission for ethanol blended biodiesel (E20 and E10) was lower than 9.15\% and 5.25\%, respectively, the ethanol blended biodiesel has shown low $\mathrm{NO}_{\mathrm{X}}$ emission and was lowest for MMEE20 blend, smoke emissions were lower $20 \%$ ethanol blended biodiesel.

Anhydrous ethanol was experimentally investigated [52] as an additive to B20 diesel oil-soybean biodiesel blends on a passenger vehicle exhaust pollutant emissions. Blends of diesel oil and soybean biodiesel with concentrations of 3\% (B3), 5\% (B5), 10\% (B10) and $20 \%$ (B20) were used as fuels. Anhydrous ethanol was added to B20 fuel blend with concentrations of $2 \%$ (B20E2) and 5\% (B20E5). The results showed that increasing biodiesel concentration in the fuel blend increased carbon dioxide $\left(\mathrm{CO}_{2}\right)$ and oxides of nitrogen $\left(\mathrm{NO}_{\mathrm{x}}\right)$ emissions, while carbon monoxide (CO), hydrocarbons (HC) and particulate matter (PM) 
emissions were reduced. The addition of anhydrous ethanol to a B20 fuel blend proved it could be a strategy to control exhaust $\mathrm{NO}_{\mathrm{X}}$ and global warming effects through the reduction of $\mathrm{CO}_{2}$ concentration. However, it may require fuel injection modifications, as it increases $\mathrm{CO}, \mathrm{HC}$ and $\mathrm{PM}$ emissions. With the addition of $2-5 \%$ of ethanol to $\mathrm{B} 20$ the $\mathrm{NO}_{\mathrm{X}}$ emission levels were reduced to that of B3. With an increased biodiesel concentration in the blend with diesel oil, reduced particulate matter emission was verified. Nevertheless, the fuel blends containing ethanol (B20E5 and B20E10) showed increased PM emission. Their results showed that the use of ethanol as an additive to biodiesel-diesel oil blends can be an ally to control $\mathrm{NO}_{\mathrm{X}}$ emissions and global warming though $\mathrm{CO}_{2}$ concentration reduction, but is unfavourable to $\mathrm{CO}, \mathrm{HC}$ and $\mathrm{PM}$ emissions.

Biodiesel from waste cocking oil blends with ethanol and methanol $[53,54]$ were run in a diesel engine under the same operating conditions and compared to a baseline diesel fuel. Overall, brake specific fuel consumption of alcohol blends was higher than for diesel, while ethanol-blended fuels show lower BSFC than methanol-blended fuels. There was no significant difference in exhaust gas temperature. Increasing alcohol concentration reduces $\mathrm{NO}$ emissions, while increasing $\mathrm{CO}$ and $\mathrm{HC}$ emissions. Biodiesel-ethanol-diesel blends, as compared to standard diesel, increase $\mathrm{CO}$ and $\mathrm{HC}$ emissions, while reducing $\mathrm{NO}$ emissions. Interestingly, biodiesel-methanol-diesel blends have opposite effects on the emissions. According to the study's results, methanol blends would be the choice if $\mathrm{CO}$ and $\mathrm{HC}$ emissions are the aim and ethanol blends would be the right choice for reducing NO emissions for the concentrations investigated in this work. Overall, emissions strongly depend on engine operating conditions and alcohol blend ratios, which could have positive and negative effects overall, due to oxygen content and cooling effects [55].

Diethyl ether (DEE), an oxygenated additive can be added to diesel/biodiesel fuels to suppress the NOx emission. DEE is an excellent ignition enhancer and has a low auto ignition temperature [56]. It is an aid for cold starting and ignition improver for diesel water emulsion [57]. Detailed experimental results reported [58] on an evaluation of the effects of using diethyl ether and ethanol as additives to biodiesel/diesel blends on the performance, emissions and combustion characteristics of a direct injection diesel engine. The test fuels are denoted as B30 (30\% biodiesel and 70\% diesel in vol.), BE-1 (5\% diethyl ether, $25 \%$ biodiesel and $70 \%$ diesel in vol.) and BE-2 (5\% ethanol, $25 \%$ biodiesel and $70 \%$ diesel in vol.) respectively. The results indicate that, compared to B30, there is a slightly lower brake specific fuel consumption (BSFC) for BE-1. Drastic reduction in smoke was observed with BE-1 and BE-2 at higher engine loads. Nitrogen oxide $\left(\mathrm{NO}_{\mathrm{X}}\right)$ emission is founded slightly higher for BE-2. Hydrocarbon (HC) emissions are slightly higher for BE-1 and BE-2, but carbon monoxide (CO) is slightly lower. The peak pressure, peak pressure rise rate and peak heat release rate of BE-1 are almost similar to those of B30, and higher than those of BE-2 at lower engine loads. At higher engine loads the peak pressure, peak pressure rise rate and peak heat release rate of BE-1 are the highest and those of B30 are the lowest. BE-1 reflects better engine performance and combustion characteristics than BE-2 and B30.

Bio-fish oil [59] blended with diethyl ether as an oxygenate additive and EGR technique was also used to improve the performance and reduce the emission of the engine. Encouraging results were obtained from their investigation. The percentage reduction in $\mathrm{CO}, \mathrm{CO}_{2}, \mathrm{NO}_{\mathrm{x}}$ and $\mathrm{C}_{\mathrm{X}} \mathrm{H}_{\mathrm{y}}$ were $91 \%, 62 \%, 92 \%$ and $90 \%$ respectively attained when the engine was run at a maximum load using BFO with $2 \%$ additive with EGR, and there was a reduction in all the percentages when the engine was run in other loads also. In the case of $\mathrm{NO}_{\mathrm{X}}$, there was an increase of this emission by about $48 \%$ in the maximum load with BFO when compared with diesel. The optimum values of the engine emission in this study were obtained with $2 \%$ of additives, when this percentage is increased or decreased the emission were increased.

In another studies [60,61] oxygenated additive diethyl ether (DEE) was blended with biodiesel in the ratios of $5 \%, 10 \%, 15 \%$ and $20 \%$ and tested for their performance. Compared with biodiesel, a reduction of $15 \%$ of $\mathrm{NO}_{\mathrm{X}}$ emission was observed for $20 \%$ DEE blends at full load, which was the highest reduction among the blend. The higher oxygen content of DEE reduced the smoke opacity. A reduction of $14.63 \%$ of smoke opacity was observed for $20 \%$ DEE blends than for biodiesel at full load. $\mathrm{HC}$ emissions were found to increase with the addition of DEE with biodiesel. This study concluded that a 20\% DEE blend with Thevetia peruviana biodiesel would result in better performance and lesser emissions than other combinations.

Performance and emission characteristics [62] of diesel engine fuelled with blends of pongamia biodiesel and diesel determined at different proportions of diethyle ether. The engine $\mathrm{NO}_{\mathrm{X}}$ emission was higher than the diesel fuel operation with all blends. The addition of diethyl ether to the blends reduced the $\mathrm{NO}_{\mathrm{X}}$ emission at low and medium loads; however, at high loads the $\mathrm{NO}_{\mathrm{X}}$ emission was higher compared to diesel and lower compared to the corresponding biodiesel blend. The addition of diethyl ether to biodiesel blends reduced both $\mathrm{NO}_{\mathrm{X}}$ and smoke emission further. The biodiesel blends tested showed a significant reduction in smoke emission. Further improvement in smoke emission was obtained by the addition of DEE. The addition of DEE resulted in a marginal deterioration of thermal efficiency. It is therefore concluded that the addition of $15 \%-20 \%$ DEE to biodiesel blends would result in a reduction of both $\mathrm{NO}_{\mathrm{X}}$ and smoke emission.

The performance and emission characteristics of diesel, (Karanja oil methyl ester) JOME biodiesel were analyzed and compared $[63,64]$ with JOME diethyl ether blends as an additive at different proportions with biodiesel in a single cylinder, four stroke naturally aspirated, computerized diesel engine. The measured performance parameters were brake thermal efficiency, brake specific fuel consumption and engine exhaust emission of $\mathrm{CO}, \mathrm{CO} 2, \mathrm{HC}, \mathrm{NO}_{\mathrm{X}}$ and smoke intensity. Significant improvements in performance parameters and exhaust emissions were observed with the addition of diethyl ether blends with biodiesel. It was concluded that 
the B-D15 was found to be the optimum blend on the basis of performance and emission characteristics.

\section{Conclusions}

Due to the continuous effort to make biodiesel fuel economically viable, as well as to use cleaner fuels, additives will become an indispensable tool in the global trade. The technical specifications of additives not only cover a wide range of subjects but also most subjects are interdependent. Additives used to improve the properties of biodiesel may further improve combustion performance of biodiesel engine. An additive used to improve ignition and combustion performances of biodiesel is advantageous to power recovery of biodiesel engine, thus it will promote economy, and meanwhile this will also improve engine power. Oxygenates additives can improve PM emissions of biodiesel, but it would not be useful for power recovery. Furthermore, small proportion of liquid chemical additive added into biodiesel and its blends with diesel can be advantageous to $\mathrm{HC}$ and $\mathrm{CO}_{2}$ emissions.

\section{Acknowledgements}

The authors would like to be obliged to Universiti Malaysia Pahang for providing laboratory facilities and financial assistance under research Grant RDU1403156.

\section{References}

1. R.D. Misra and M.S. Murthy, Renewable and Sustainable Energy Reviews 14, 3005 (2010).

2. A.H. Demirbas and I. Demirbas, Energy Convers Manage 48, 2386 (2007).

3. A. Demirbas, Progress in Energy and Combustion Science 33, 1 (2007).

4. Ali OM, Mamat R, Faizal CKM. International Review of Mechanical Engineering 6, 1573-80 (2012).

5. M.K. Lam, K.T. Tan, K.T. Lee, and A.R. Mohamed, Renewable and Sustainable Energy Reviews 13, 1456 (2009).

6. A.K. Babu and G. Devaradjane, SAE Technical Paper 2003-01-07, 10.4271/2003 (2003).

7. J. Krahl, A. Munack, O. Schroder, H. Stein, and J. Bunger, SAE Technical Paper 2003-01-31, 10.4271/2003 (2003).

8. H. Jon, G. Van, L.P. Charles, and C.E. G, in Agricultural Equipment Technology Conference (ASABE, USA, 2007), pp. 1-22.

9. A.B. Syed and K.R. Gopal, Renewable and Sustainable Energy Reviews 16, 711 (2012).

10. A.E. Atabani, A.S. Silitonga, I.A. Badruddin, T.M.I. Mahlia, H.H. Masjuki, and S. Mekhilef, Renewable and Sustainable Energy Reviews 16, 2070 (2012).
11. Ali OM, Mamat R, Abdullah NR, Abdullah AA., Renewable Energy 86, 59-67 (2016).

12. R. Edward, J.F. Larive, and V.R.P., JRC Scientific and Technical Reports 3c, (2011).

13. A.K. Agarwal, Progress in Energy and Combustion Science 33, 233 (2007).

14. M. Canakci, A.N. Ozsezen, E. Arcaklioglu, and A. Erdil, Expert Syst. Appl. 36, 9268 (2009).

15. C. Carraretto, A. Macor, A. Mirandola, A. Stoppato, and S. Tonon, Energy 29, 2195 (2004).

16. C. Robbins, S.K. Hoekman, E. Ceniceros, and M. Natarajan, SAE Technical Paper 2011-01-19, 10.4271/2011 (2011).

17. S.K. Hoekman, A. Broch, C. Robbins, and E. Ceniceros, Desert Research Institute (2011).

18. A. Demirbas, Energy Educ Sci Technol 21, 1 (2008).

19. P.C. Smith, Y. Ngothai, Q.D. Nguyen, and B.K. O'neill, Renewable Energy 35, 1145 (2010).

20. Ali OM, Mamat R, Faizil CKM., Applied Mechanics and Materials 465-466, 137-41 (2014).

21. J.E. Chandler, F.G. Horneck, and G.I. Brown, SAE Technical Paper 922186, 10.4271/922186 (1992).

22. G. Knothe, J. Krahl, and G.J. Van, The Biodiesel Handbook (Champaign, IL: AOCS Press; 2004, 2004).

23. R.O. Dunn, M.W. Shockley, and M.O. Bagby, J Am Oil Chem Soc 73, 1719 (1996).

24. Ali OM, Mamat R, Faizal CKM., Journal of Renewable and Sustainable Energy 5, 012701 (2013).

25. A.C. Pinto, L.L.N. Guarieiro, M.J.C. Rezende, N.M. Ribeiro, E.A. Torres, W.A. Lopes, P.A.P. Pereira, and J.B.J. De Andrade, Chem. Soc. 16, 1313 (2005).

26. A.I. Nor, M.N. Fitihamin, I. Razali, M. Suhalia, and Chek, Journal of Oil Palm Research 20, 517 (2008).

27. Ali OM, Mamat R, Faizil CKM., Applied Mechanics and Materials 465-466, 130-6 (2014).

28. T.C. Ming, N. Ramli, O.T. Lye, M. Said, and Z. Kasim, European Journal of Lipid Science and Technology 107, 505 (2005).

29. H. Noureddini, Chemical and Biomolecular Engineering Research and Publications (2002).

30. W.H. LIM, T.L. OOI, and H.K. HONG, Journal of Oil Palm Research. 21, 683 (2009).

31. H. Tang, A. Wang, S.O. Salley, and N.K. Simon, J Am Oil Chem Soc 85, 373 (2008).

32. R.O. Dunn, Fuel Process Technol 86, 2005 (2005).

33. R.L. Mccormick, J.R. Alvarez, and M.S. Graboski, National Renewable Energy Laboratory, (2003).

34. G. Suyin and K.N. Hoon, Energy Conversion and Management 51, 1536 (2010).

35. M.F. David, S.S. Dalyelli, M.P. Flaysner, M.N.A. Rosana, A.A.M. Rodrigo, and G.H.T. Manuel, Fuel 97, 658 (2012).

36. K. Varatharajan, M. Cheralathan, and R. Velraj, Fuel 90, 2721 (2011).

37. Y.C. Liang, C.Y. May, C.S. FoonOON, M.A. Ngan, C.C. Hock, and Y. Basiron, Fuel 85, 867 (2006).

38. Ali OM, Yusaf T, Mamat R, Abdullah N, Abdullah A., Energies 7, 4364-80 (2014).

39. J.P. Szybist, A.L. Boehman, J.D. Taylor, and L.R. Mccormick, Fuel Process Technol 86, 1109 (2005). 
40. Ali OM, Mamat R, Faizal CKM., Applied Mechanics and Materials 393, 487-92 (2013).

41. M.A. Kalam and H.H. Masjuki, Biomass Bioenerg 32, 1116 (2008).

42. M. Shahabuddin, H.H. Masjuki, M.A. Kalam, M. Mofijur, M.A. Hazrat, and A.M. Liaquat, Energy Procedia 14, 1624 (2012).

43. R.P. Venkateswara, B. V Appa Rao, and D. Radhakrishna, International Journal of Advanced Engineering Research and Studies I, 217 (2011).

44. R.P. Venkateswara, B. V Appa Rao, and D. Radhakrishna, Iranica Journal of Energy \& Environment 3, 109 (2012).

45. R.P. Venkateswara, B. V Appa Rao, and D. Radhakrishna, International Journal of Energy and Environment. 3, 629 (2012).

46. Ali OM, Mamat R, Abdullah NR, Abdullah A., Journal of Biobased Materials and Bioenergy 9, 10841 (2015).

47. G. Labeckas and S. Slavinskas, Energy Convers Manage 46, 1731 (2005).

48. K.S. Chen, Y.C. Lin, L. Te Hsieh, L.F. Lin, and C.C. Wu, Energy 35, 2043 (2010).

49. M.D. Kass, M.M. Swartz, S.S. Lewis, S.P. Huff, and D.W. Lee, American Society of Agricultural and Biological Engineers (2006).

50. H. Joshi, B.R. Moser, J. Toler, W.F. Smith, and T. Walker, Renewable Energy 35, 2207 (2010).

51. P. V Bhale, N. V Deshpande, and B.S. Thombre, Renewable Energy 34, 794 (2009).

52. L.R. Mario and R.S. Jose, Fuel 90, 98 (2011).

53. N. Yilmaz, Energy 40, $210 \quad$ (2012).
54. C.S. Lei Zhu, W.G. Cheung, and Z.H. Zhang, Science of the Total Environment 408, 914 (2010).

55. Ali OM, Mamat R, Abdullah NR, Abdullah AA., AIP Conf Proc 1660, 070006-1-070006-11 (2015).

56. N.K. Miller jothi and S. Nagarajan, G. Renganarayanan, International Journal of Thermal Sciences 47, 450 (2008).

57. K.A. Subramanian and R. A., SAE Paper 2002-0127, 10.4271/2002 (2002).

58. D.H. Qi, H. Chen, L.M. Geng, and Y.Z. Bian, Renewable Energy 36, 1252 (2011).

59. C. Swaminathan and J. Sarangan, Biomass and Bioenergy. 39, 168 (2012).

60. T.K. Kannan and R. Marappan, European Journal of Scientific Research 43, 563 (2010).

61. T.K. Kannan and R. Marappan, Journal of Applied Sciences. 11, 2961 (2011).

62. M. Pugazhvadivu and S. Rajagopan, Indian Journal of Science and Technology 2, 31 (2009).

63. S. Sivalakshmi and T. Balusamy, in PEA-AIT International Conference on Energy and Sustainable Development: Issues and Strategies (ESD 2010) (Thailand, 2010), pp. 2-4 June 2010.

64. J.P. Iranmanesh, M. Subrahmanyam and M.K.G. Babu, SAE Paper 28 (2008). 